\title{
Pharmacological Effects of Phosphatidylserine Enzymatically Synthesized from Soybean Lecithin on Brain Functions in Rodents
}

\author{
Masashi SAKaI, Hideyuki Yamatoya, and Satoshi Kudo \\ Yakult Central Institute for Microbiological Research, \\ Tokyo 186, Japan \\ (Received July 17, 1995)
}

\begin{abstract}
Summary Soybean transphosphatidylated phosphatidylserine (SBtPS) was prepared from soybean phosphatidylcholine by transphosphatidylation using phospholipase $\mathrm{D}$, and the fatty acids composition and pharmacological properties were compared with those of bovine brain cortex-derived phosphatidylserine (BC-PS) which was reported to improve cognitive disorders of senile dementia patients by oral administration $(300 \mathrm{mg} /$ day $)$. The molecular species of SB-tPS are rich in linoleic and palmitic acids whereas those of BC-PS are stearic and oleic acids. Despite the differences in fatty acid composition, SB-tPS displayed significant activities on the increase in brain glucose concentrations in mice (79 $\mathrm{mg} / \mathrm{kg}$, i.v.) and the restoration of scopolamine-induced amnesia in rats $(60 \mathrm{mg} / \mathrm{kg}$, i.p.) as did BC-PS. These results suggest the possibility that SB-tPS may prevent and/or improve senile dementia by oral administration.
\end{abstract}

Key Words phosphatidylserine, soybean lecithin, transphosphatidylation, brain, dementia, scopolamine, passive avoidance, glucose, rat, mouse

In 1986, it was first reported that the oral administration $(300 \mathrm{mg} /$ day $)$ of bovine brain cortex-derived phosphatidylserine (BC-PS) to patients with senile dementia improved their cognitive disorders (1). Since then, the effectiveness of this phospholipid has been confirmed by several double-blind, placebo-controlled studies in Europe and the USA (2-5). Especially, one recent clinical trial on 494 elderly patients (3) demonstrated the benefit of taking BC-PS as an anti-dementia agent improving the behavior and cognitive performance without remarkable side effects.

It is known that phosphatidylcholine (PC) can also improve cognitive disorders. However, unlike BC-PS, the anti-dementia effects of PC have been proven by a combination with cholinesterase inhibitors such as tetrahydroaminoacridine, and the efficacy dose of PC was about 30 times larger than that of BC-PS (6). Therefore, the anti-dementia mechanism of BC-PS would be different from that of 
PC which is considered to improve brain function by supplying choline for acetylcholine synthesis.

The efficacy dose of BC-PS ( $300 \mathrm{mg} /$ day) is not extraordinarily higher than the estimated daily intake $(80 \mathrm{mg})(7)$, therefore, it could be possible to claim this phospholipid as a food supplement to prevent and/or improve senile dementia. However, in terms of safety, the brain cortex is not a suitable material for food use, because some encephalopathies such as mad cow disease (bovine spongiform encephalopathy) or Kuru disease in humans are orally infectious through prion contaminated brain ( 8$)$. In addition, the content of phosphatidylserine in brain cortex is small (about $3 \mathrm{~g}$ /one bovine brain cortex) (9) and there are no known natural and safe sources which contain phosphatidylserine in amounts adequate for use as a food supplement.

To overcome these problems, a transphosphatidylation reaction using phospholipase D (10) was applied to produce phosphatidylserine from soybean lecithin. In this reaction, $\mathrm{PC}$ is a donor of phosphatidyl residue and L-serine is an acceptor. However, the fatty acid composition of the transphosphatidylated phosphatidylserine from soybean lecithin is probably different from that of BC-PS, the structure of which is mainly confined to a 1-stearoyl-2-oleoyl-sn-glycero-3-phosphoserine. Therefore, we investigated the pharmacological activities of soybean transphosphatidylated phosphatidylserine (SB-tPS) in rodents in comparison with those of BC-PS to evaluate the suitability of SB-tPS as a dementia-preventing food supplement.

\section{MATERIALS AND METHODS}

Materials. Soybean phosphatidylcholine $\left(\mathrm{PC} 80^{\mathrm{TM}}\right)$ was purchased from Croklaan b.v. (Wormerveer, Holland) and BC-PS was from Avanti Polar-Lipids, Inc. (Alabaster, USA). Phospholipase D (PLD-Y1) was obtained from the cultured medium of Streptomyces prunicolor (11). All other chemicals were of analytical grade or the highest quality commercially available.

Preparation of SB-tPS. $\quad \mathrm{PC}^{\mathrm{TM}}$ in ethylacetate $(10 \mathrm{~g}$ in $20 \mathrm{ml})$ and $\mathrm{L}$-serine in $0.10 \mathrm{M}$ phosphate buffer $(1.2 \mathrm{~g}$ in $5.8 \mathrm{ml}, \mathrm{pH} 7.0)$ were mixed with 1,500 units of PLD-Y1 and incubated at $50^{\circ} \mathrm{C}$ for $5 \mathrm{~h}$. The resultant phosphatidylserine was purified on a silica gel column using hexane-isopropanol-water $(60: 80: 14)$ as a separating solvent.

Preparation of lysophosphatidylserine. Phosphatidylserine (SB-tPS or BC-PS) in ethylacetate $\left(300 \mathrm{mg}\right.$ in $1.2 \mathrm{ml}$ ) was mixed with $250 \mathrm{IU}$ of phospholipase $\mathrm{A}_{2}$ (Lecitase $^{\mathrm{TM}} 10 \mathrm{~L}$, Novo Nordisk A/S, Denmark) in $1.42 \mathrm{ml}$ of $35 \mathrm{~mm}$ phosphate buffer ( $\mathrm{pH} 7.4$ ), and incubated at $50^{\circ} \mathrm{C}$ for $14 \mathrm{~h}$. The enzyme was inactivated in boiling water before precipitating the lysophosphatidylserines with acetone to remove liberated fatty acids.

Preparation of sodium salt of SB-tPS. SB-tPS $(6 \mathrm{~g})$ dissolved in $200 \mathrm{ml}$ of chloroform-methanol $(3: 2$, by vol.) was mixed with $50 \mathrm{ml}$ of $50 \mathrm{~mm}$ Tris- $\mathrm{HCl}$ 
buffer ( $\mathrm{pH} \mathrm{7.8,} \mathrm{containing} 2 \mathrm{M} \mathrm{NaCl}$ ). The resultant lower phase containing the sodium salt of SB-tPS was evaporated to dryness.

Determination of fatty acid composition. Fatty acids were determined by gas-liquid chromatography after methylation. The analysis was carried out on a gas chromatograph with a flame-ionization detector (Hewlett-Packard, Avondal, USA). The temperatures of the detector, an injection port and a column were maintained at 240,250 and $230^{\circ} \mathrm{C}$, respectively. A stainless-steel column, $30 \mathrm{~m} \times$ $0.25 \mathrm{~mm}$ (inside diameter), packed with crosslinked polyethylene glycol (HPINNOWAX $^{\mathrm{TM}}$, Hewlett-Packard) was used to separate the individual fatty acid methyl esters. Peaks were identified by comparing the retention times of samples with those of methyl esters standards (Sigma Chemical Co., USA) under identical conditions.

Measurement of brain and serum glucose concentrations. The dispersion of phosphatidylserine or lysophosphatidylserine was injected in the tail veins of male mice (ICR strain, 8 weeks, ca. $35 \mathrm{~g}$ ), and $30 \mathrm{~min}$ later the animals were sacrificed by decapitation and blood samples were collected. The separated heads were dropped into liquid nitrogen and the frozen brains were removed. Isolated brains were pulverized with glacial perchloric acid solution and neutralized with potassium hydroxide solution. After removing the precipitate by centrifugation, brain glucose concentrations were measured by the hexokinase method (F-kit D-glucose, Boehringer Mannheim GmbH, Germany). On the other hand, the glucose concentrations in the serum were measured by the glucose oxidase method (Glucose B-test, Wako Pure Chemical Industries, Ltd., Japan). The results were analysed by Tukey's multiple comparison test.

Evaluation of the restoration of scopolamine-induced amnesia by phosphatidylserine. Restoration of scopolamine-induced amnesia was evaluated by the passive avoidance behavior test in a step-though type situation, according to Zanotti et al. (12) with some modifications. Briefly, on the first day, a male rat (SpragueDawley, 9 weeks, ca. $300 \mathrm{~g}$ ) was placed in a dark chamber with a guillotine door to a lighted chamber for $2 \mathrm{~min}$. Then the rat was transferred to the lighted chamber and allowed to enter the dark chamber (a step-through trial). On the next day, scopolamine hydrobromide $(3.0 \mathrm{mg} / \mathrm{kg}$ body weight, Sigma Chemical Co., USA) and the sodium salt of phosphatidylserine $(60 \mathrm{mg} / \mathrm{kg}$ body weight, BC-PS or SB-tPS) were given intraperitoneally and the step-through trials were done twice. On the 2 nd trial ( $20 \mathrm{~min}$ after injection of scopolamine and phosphatidylserine), the rat received a single 2-s unavoidable scrambled foot shock (DC, $4.0 \mathrm{~mA}$ ) on a grid floor immediately after entering the dark chamber. Retention of the memory was tested $24 \mathrm{~h}$ after the injection of the samples by placing the animal in the lighted chamber and recording the latency to reenter the dark chamber. 
Table 1. Molecular species of phosphatidylserine (weight \%).

\begin{tabular}{|c|c|c|c|c|c|c|c|c|c|}
\hline & \multicolumn{9}{|c|}{ Fatty acid } \\
\hline & $16: 0$ & $18: 0$ & $18: 1$ & $18: 2$ & $18: 3$ & $20: 4$ & $20: 5$ & $22: 6$ & others \\
\hline PC80 ${ }^{\mathrm{TM}}$ (Total) & 14.1 & 4.0 & 9.5 & 64.5 & 6.0 & nd & nd & nd & 1.9 \\
\hline SB-tPS (Total) & 15.0 & 4.2 & 9.4 & 63.8 & 5.8 & nd & nd & nd & 1.8 \\
\hline (1-position) & 35.9 & 8.8 & 7.5 & 40.0 & 3.1 & nd & nd & nd & 4.7 \\
\hline (2-position) & 3.5 & 0.5 & 10.6 & 76.6 & 7.0 & nd & nd & nd & 1.8 \\
\hline BC-PS (Total) & 2.0 & 44.2 & 43.2 & nd & nd & 0.2 & 0.5 & 0.4 & 9.5 \\
\hline (1-position) & 2.7 & 87.9 & 2.0 & nd & nd & nd & 1.0 & nd & 6.4 \\
\hline (2-position) & 1.2 & 9.5 & 72.2 & nd & nd & 0.3 & 0.1 & 0.7 & 16.0 \\
\hline
\end{tabular}

The fatty acids compositions at 1-position were determined after digestion with phospholipase $\mathbf{A}_{2}$. nd: not detected.

Table 2. Effects of SB-tPS or Lyso-SB-tPS injection into mice tail veins on glucose concentrations in brain.

\begin{tabular}{lll}
\hline Samples & $($ doses $)$ & $\begin{array}{c}\text { Brain glucose } \\
(\mu \mathrm{mol} / \mathrm{g} \text { wet wt. })\end{array}$ \\
\hline Control & & $0.8 \pm 0.2(n=5)^{\mathrm{a}}$ \\
SB-tPS & $(79 \mathrm{mg} / \mathrm{kg})$ & $3.2 \pm 0.5(n=5)^{\mathrm{b}}$ \\
Lyso-SB-tPS & $(51 \mathrm{mg} / \mathrm{kg})^{\#}$ & $2.2 \pm 1.2(n=6)^{\mathrm{b}}$ \\
\hline
\end{tabular}

Values are $\mathbf{M} \pm \mathbf{S D}$. Values with unlike superscript letters were significantly different by Tukey's multiple comparison test $(p<0.05)$. "Comparable to that of SB-tPS on molar basis.

\section{RESULTS}

Fatty acid composition of $S B$ - $t P S$

As show in Table 1, the fatty acid composition of SB-tPS was almost identical with that of $\mathrm{PC} 80^{\mathrm{TM}}$ from which SB-tPS was made, but was different from that of BC-PS. With respect to 1-position fatty acids, SB-tPS mainly possesses linoleic acid (40.0\%) or palmitic acid (35.9\%) whereas most of BC-PS comprises stearic acid (87.9\%). Regarding the 2-position, SB-tPS comprises mostly linoleic acid (76.6\%) while BC-PS comprises oleic acid (72.2\%).

Increase of the glucose concentration by intravenous injection of phosphatidylserine or lysophosphatidylserine into mice

As shown in Tables 2 and 3, intravenous injection of SB-tPS or lyso-SB-tPS (lysophosphatidylserine from SB-tPS) into mice tail veins significantly increased the glucose concentrations in both the brain and serum, although the level of lyso-SB-tPS was somewhat lower than that of lyso-BC-PS (Table 3). 
Table 3. Effects of lysophosphatidylserines injection into mice tail veins on glucose concentrations in their brain or serum.

\begin{tabular}{llcc}
\hline Samples & (doses) & $\begin{array}{c}\text { Brain glucose } \\
(\mu \mathrm{mol} / \mathrm{g} \text { wet wt. })\end{array}$ & $\begin{array}{c}\text { Serum glucose } \\
(\mathrm{mM})\end{array}$ \\
\hline Control & & $0.8 \pm 0.2(n=6)^{\mathrm{a}}$ & $11.9 \pm 0.7(n=5)^{\mathrm{a}}$ \\
Lyso-BC-PS & $(10 \mathrm{mg} / \mathrm{kg})$ & $3.2 \pm 0.9(n=7)^{\mathrm{c}}$ & $22.6 \pm 3.4(n=7)^{\mathrm{b}}$ \\
Lyso-SB-tPS & $(10 \mathrm{mg} / \mathrm{kg})$ & $1.8 \pm 0.8(n=6)^{\mathrm{ab}}$ & $18.4 \pm 5.1(n=6)^{\mathrm{ab}}$ \\
Lyso-SB-tPS & $(30 \mathrm{mg} / \mathrm{kg})$ & $2.5 \pm 0.2(n=5)^{\mathrm{bc}}$ & $21.8 \pm 1.6(n=6)^{\mathrm{b}}$ \\
\hline
\end{tabular}

Values are $\mathbf{M} \pm \mathbf{S D}$. Values with unlike superscript letters were significantly different by Tukey's multiple comparison test $(p<0.01)$.

Table 4. Effects of intraperitoneal injection of phosphatidylserines $(60 \mathrm{mg} / \mathrm{kg})$ on the scopolamine-induced amnesia measured by passive avoidance behavior of rats.

\begin{tabular}{llcccc}
\hline \multirow{2}{*}{ Groups } & \multirow{2}{*}{ Treatments } & \multicolumn{3}{c}{$\begin{array}{c}\text { Distribution of the } \\
\text { reaction latency }(\mathrm{s})\end{array}$} & \multirow{2}{*}{$p^{\mathrm{b})}$} \\
\cline { 3 - 5 } & & $0-30$ & $31-300$ & $>300$ & \\
\hline 1 & Control & $0 / 8^{\mathrm{a}}$ & $0 / 8$ & $8 / 8$ & $<0.01$ \\
2 & Scopolamine & $9 / 15$ & $2 / 15$ & $4 / 15$ & - \\
3 & Scopolamine + BC-PS & $1 / 10$ & $2 / 10$ & $7 / 10$ & $<0.05$ \\
4 & Scopolamine + SB-tPS & $1 / 16$ & $5 / 16$ & $10 / 16$ & $<0.01$ \\
\hline
\end{tabular}

a) Rats distributed/rats tested. ${ }^{\text {b) }} p$ values of difference from group 2 (treated with scopolamine alone) determined by the Mann Whitney's $U$-test.

Restoration of scopolamine-induced amnesia in rats by intraperitoneal injection of phosphatidylserine

As shown in Table 4, 9 out of 15 rats treated with scopolamine alone entered the dark chamber within $30 \mathrm{~s}$, whereas all of the control rats given Tris- $\mathrm{HCl}$ buffer stayed in the lighted chamber over $300 \mathrm{~s}$. When phosphatidylserine (SB-tPS or BC-PS) and scopolamine were administered into different points of an abdomen, the latency of the majority of mice exceeded $300 \mathrm{~s}$. Consequently, the reaction latency was significantly prolonged compared with the group treated with scopolamine alone ( $p<0.01$ for SB-tPS, $p<0.05$ for BC-PS).

\section{DISCUSSION}

In the present study, the pharmacological action of SB-tPS was compared with that of BC-PS which reportedly improves cognitive disorders of senile dementia patients. So far, it is not clear whether or not the pharmacological actions of phospholipids containing completely different molecular species from BC-PS, like SB-tPS (Table 1), are similar to BC-PS.

Bruni et al. (13) first reported that the intravenous injection of BC-PS 
increased the brain glucose concentrations of mice. In addition, it was proven that a lyso-form of BC-PS was similarly active (14). As shown in Tables 2 and 3, SB-tPS or lyso-SB-tPS significantly increased the serum and brain glucose concentrations, indicating that the pharmacological activity of those soybean phospholipid derivatives are comparable to BC-PS. The serum glucose augmentation by BC-PS was suppressed by an adrenolytic agent (13), and was not observed in mast celldeficient mice (14), which may reflect adrenaline-induced hepatic glycogenolysis through mast cell activation. While this hyperglycemic state is one of the most plausible reasons for the brain glucose augmentation, a reduced energy-expenditure accompanied with a diminished carbohydrate catabolism is also possible, because the efficiency of the oxidative phosphorylation in the brains of Alzheimer's disease patients was lower than that of normal subjects (15).

Contrary to our results, the purified soybean phosphatidylserines (soybean PS) were reported to have little or no effect on the glucose state (13), though we cannot explain this inconsistency.

Zanotti et al. (16) reported that the intraperitoneal injection of BC-PS restored scopolamine-induced amnesia in rats, which seemed to offer a clue to the antidementia mechanism of phosphatidylserine. Because scopolamine is an acetylcholine receptor antagonist, the results in Table 4 suggest that SB-tPS affects on brain acetylcholine metabolism. Casamenti et al. (17) reported that the successive administration of BC-PS reversed the age-dependent decrease in cortical acetylcholine release in rats; therefore, SB-tPS may also improve memory dysfunction in aged animals by ameliorating their acetylcholine release.

Up until now, no information has been available about the pharmacological properties of phosphatidylserines other than BC-PS and soybean PS. Furthermore, it is not yet clear whether or not the characteristic stearoyloleate of BC-PS is an essential structure for its actions on brain functions. The present data show that SB-tPS has almost the same activities as BC-PS in regards increasing the brain glucose concentration and restoring scopolamine-induced amnesia, which suggests that a specific combination of fatty acids is not necessarily required for the improvement of brain function.

Although the chronic oral treatment of BC-PS to aged rats (16) or neonatal mice $(18)$ has already been reported to improve cognitive abilities, further animal experiments, especially oral treatment of SB-tPS, are needed to confirm the usefulness of SB-tPS as an anti-dementia food material.

The authors wish to thank Ms. N. Mizusawa for her technical assistance. We are also grateful to Dr. M. Onoue and Mr. K. Kojima in our laboratory for their kind arrangement to carry out animal experiments.

\section{REFERENCES}

1) Delwaide, P. J., Gyselynck-Mambourg, A. M., Hurlet, A., and Ylieff, M. (1986): 
Double-blind randomized controlled study of phosphatidylserine in senile demented patients. Acta Neurol. Scand., 73, 136-140.

2) Amaducci, L., and the SMID group (1988): Phosphatidylserine in the treatment of Alzheimer's disease: Results of a multicenter study. Psychopharmacol. Bull., 24, 130134.

3) Cenacchi, T., Bertoldin, T., Farina, C., Fiori, M. G., Crepaldi, G., and participating investigators (1993): Cognitive decline in the elderly: a double-blind, placebocontrolled multicenter study on efficacy of phosphatidylserine administration. Aging Clin. Exp. Res., 5, 123-133.

4) Crook, T., Tinklenberg, J., Yesavage, J., Petrie, W., Nunzi, M. G., and Massari, D. (1991): Effects of phosphatidylserine in age-associated memory impairment. Neurology, 41, 644-649.

5) Engel, R. R., Satzger, W., Günther, W., Kathmann, N., Bove, D., Gerke, S., Münch, U., and Hippius, H. (1992): Double-blind cross-over study of phosphatidyl-serine vs. placebo in patients with early dementia of Alzheimer type. Eur. Neuropsychopharmacol., 2, 149-155.

6) Eagger, S. A., Levy, R., and Sahakian, B. J. (1991): Tacrine in Alzheimer's disease. Lancet, 337, 989-992.

7) Bruni, A., Mietto, L., Bellini, F., Boarato, E., and Toffano, G. (1989): Pharmacological and autopharmacological action of phosphatidylserine, in Phospholipids in the Nervous System (Fidia Research Series 17), ed. by Bazan, N. G., Horrocks, L. A., and Toffano G., Liviana Press, Padova, pp. 217-224.

8) Prusiner, S. B. (1991): Molecular biology of prion disease. Science, 252, 1515-1521.

9) Weihrauch, J. L., and Son, Y. S. (1983): The phospholipids content of foods. J. Am. Oil Chem. Soc., 60, 1971-1978.

10) Kudo, S. (1987): Biosurfactants as food additives. World Confer. Biotech. Fat and Oil Ind., Hamburg, September, Proceedings by Am. Oil Chem. Soc., 195-201.

11) Sawada, H., Watanabe, T., Motoike, M., Kudo, S., and Kuroda, A. (1988): The phospholipase D showing transphosphatidylation activity. Abstracts of Papers, the Annual Meeting of the Japan Society for Bioscience, Biotechnology, and Agrochemistry, Nagoya, April, p. 415 (in Japanese).

12) Zanotti, A., Valzelli, L., and Toffano, G. (1986): Reversal of scopolamine-induced amnesia by phosphatidylserine in rats. Psychopharmacol. Berl., 90, 274-275.

13) Bruni, A., Toffano, G., Leon, A., and Boarato, E. (1976): Pharmacological effects of phosphatidylserine liposomes. Nature, 260, 331-333.

14) Chang, H. W., Inoue, K., Bruni, A., Boarato, E., and Toffano, G. (1988): Stereoselective effects of lysophosphatidylserine in rodents. Br. J. Pharmacol., 93, 647-653.

15) Sims, N. R., Finegan, J. M., Blass, J. P., Bowen, D. M., and Neary, D. (1987): Mitochondrial function in brain tissue in primary degenerative dementia. Brain Res., 436, 30-38.

16) Zanotti, A., Valzelli, L., and Toffano, G. (1989): Chronic phosphatidylserine treatment improves spatial memory and passive avoidance in aged rat. Psychopharmacol. Berl., 99, 316-321.

17) Casamenti, F., Scali, C., and Pepeu, G. (1991): Phosphatidylserine reverses the age-dependent decrease in cortical acetylcholine release: a microdialysis study. Eur. $J$. Pharmacol., 194, 11-16. 
18) Ammassari-Teule, M., Fagioli, S., Maritati, M., Populin, R., and Pavone, F. (1990): Chronic administration of phosphatidylserine during ontogeny enhances subjectenvironment interactions and radial maze performance in C57BL/6 mice. Physiol. Behav., 47, 755-760. 